\title{
THE KOLAHOI NORTHERN GLACIER, KASHMIR
}

\author{
By N. E. Odell \\ (Clare College, Cambridge, England)
}

During a visit on $3^{1}$ August I $_{96}$ I to this glacier, which is situated about 35 miles $(56 \mathrm{~km}$.) east-north-east of Srinagar, it was noticeable that a considerable recession of the snout had taken place since its position was as shown on the one-inch Survey map of 1912, and also on the reduced half-inch sheets of 1922 and 1943 , all of which are still in current, but politically restricted, use. There has been retreat in the interval of about half a mile $(0 \cdot 8 \mathrm{~km}$. $)$, i.e. from the lower open valley to the vicinity of the north face of Mt. Kolahoi, where it descends

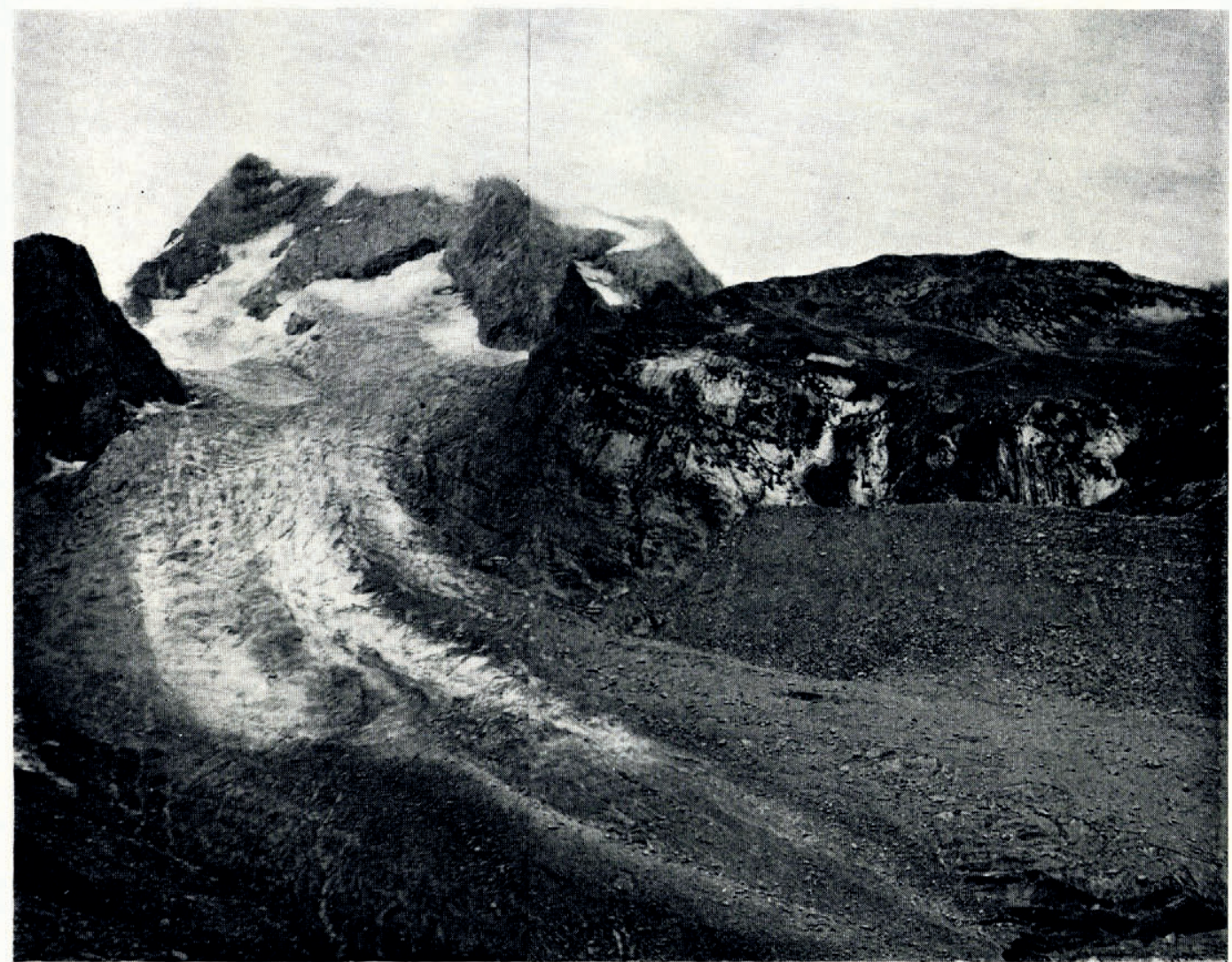

Fig. I. Lower part of Kolahoi northern glacier in 1961 from the north-east. Photograph by $\mathcal{N}$. E. Odell

in an ice fall fed chiefly by the upper glacier basin to the west. The present altitude of the snout is about $12,000 \mathrm{ft}$. $(3,660 \mathrm{~m}$.), in relation to the contours on the above maps; and the lower reaches of the glacier at any rate are in a very passive and shrinking condition. Time and opportunity after a four days' trek from Srinagar (via Pahlgam and the West Liddar valley) did not permit of examination of the uppermost reaches of the glacier, particularly that branch, now the main stream, having its source on the west side of the mountain. Panoramic photographs were taken by Major R. E. Rawle and the writer to show the present terminal conditions, and an example of these is reproduced as Figure $\mathrm{I}$. 
Several glaciers radiate from Mt. Kolahoi, of which the largest is the main Kolahoi Glacier, flowing along the west and then the north-east side of the peak. It is joined by a considerable tributary, now greatly shrunk, from the névé lying on the east side. That recession has been going on for many years is evident from Dr. E. F. Neve's account in his book, Beyond the Pir Panjal, p. I56; and also in the Alpine Fournal, Vol. 25, No. I87, I910, p. 40: "Mt. Kolahoi \& its northern glacier." He says: "This glacier has receded quite a quarter of a mile since my first visit in I 887. The trigonometrical survey map was completed in 1857 . Reference to this and to the relative position of the side streams, especially one which descends from a small lake $\mathrm{I}, 000 \mathrm{ft}$. [305 m.] above the valley, shows that since that date, in fifty-two years,

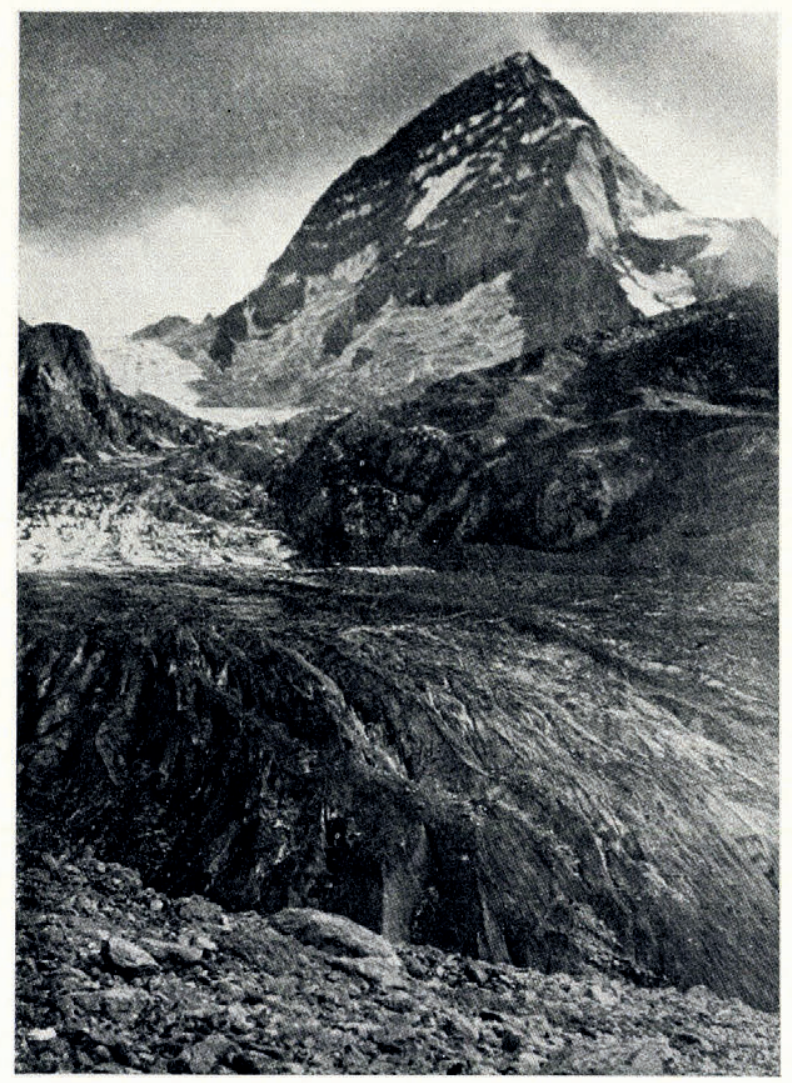

Fig. 2. Mount Kolahoi (north face) and lower extension of the Kolahoi northern glacier in Igog. Photograph by E. F. Neve. Reproduced from the Alpine Journal, Vol. 25, No. 187, 1910

the glacier must have retreated above a mile." To this, as far as any records go, may be added the recession of half a mile since 1912 , which is cited above. It would seem, moreover, from Dr. Neve's account of conditions in r 909 , that the main head-snows of the Kolahoi Glacier were then situated in what is now the shrunken tributary from the névé on the east side of Mt. Kolahoi; whereas at the present time the principal feeder of the glacier derives from the west side of the peak. The photographs accompanying Dr. Neve's article are of considerable interest as showing the much greater extent of the ice in 1909 than at present. Two of these are here reproduced (Figs. 2 and 3 ). 
Incidentally, Mt. Kolahoi, I 7,799 ft. (5,424 m.), is the highest peak of the range which lies along the north-east side of the valley of Kashmir. In I 9 I I the main peak, with approach from the east, was ascended to within $30 \mathrm{ft}$. $(9 \mathrm{~m}$.) of the top by Capt. J. B. Corry, R.E., and Lieut. R. D. Squires; and the following year the actual summit was reached by the same route by Dr. E. F. Neve and Lieut. (later Professor) K. Mason, R.E. (Alpine Fournal, Vol. 25, No. I94, I9I I, p. 68I ; and Vol. 26, No. I98, 1912, p. 407). It was Mason who was responsible, as he has informed me, for the early plane-table survey of Kolahoi and its glaciers, which supplied the data for the one-inch Survey map of I9 22 cited above.

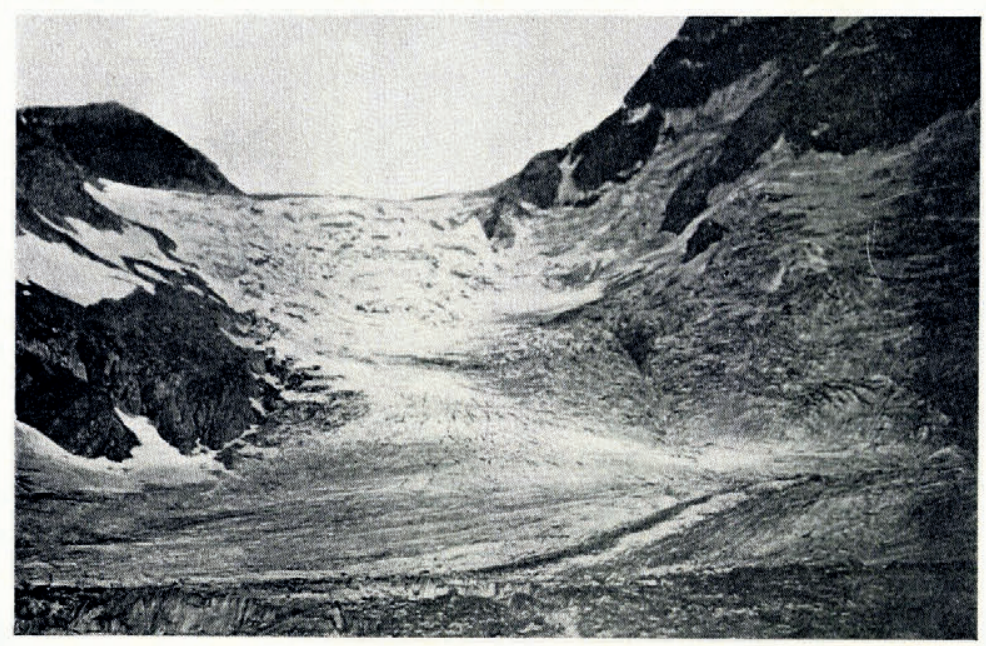

Fig. 3. The third ice fall of the Kolahoi northern glacier in 1909: original head-snows but now tributary to the main trunk stream from right of picture. Photograph by E. F. Neve. Reproduced from the Alpine Journal, Vol. 25, No. I87, 1910

It is much to be hoped that surveyors, officers of the Geological Survey of India, or other travellers will take greater interest in the marked glacial changes that are going on in these mountains, as well as in those of the Pir Panjal Range on the south-west side of the valley of Kashmir. Records available are too scanty at the present time.

MS. received 8 fanuary 1963 